\title{
Modern youth's value orientations and activity in a cross-cultural context
}

\author{
Inna Atamanova ${ }^{1, *}$, Sergey Bogomaz ${ }^{1}$, and Tatyana Filippova ${ }^{2}$ \\ ${ }^{1}$ National Research Tomsk State University, Tomsk, Russia \\ ${ }^{2}$ Karaganda State Technical University, Karaganda, Kazakhstan
}

\begin{abstract}
Addressing the issue of youth's personal and professional development, taking into account their value orientations and psychological characteristics of their activity, seems to be relevant to the modern world's challenges. Cultural dimensions are believed to be the very factors that can contribute to a better understanding of the interplay between personal and environmental aspects when analysing the problem of high quality human resource development. The paper presents a cross-cultural study on cultural values characterising socio-economic and cultural settings of two countries and university students' basic values and parameters of their personal potential in the context of their activity. 307 university students from Tomsk (Russia) and 295 university students from Karaganda (Kazakhstan) participated in the study. The research tools involved a number of questionnaires aimed at exploring cultural dimensions, subjective evaluation of realisation of basic values in the urban environment and parameters of personal potential as factors of one's psychological system of activity. The study results revealed a number of statistically significant differences among the study participants. First, there was a difference in some cultural values, namely individualism, uncertainty avoidance and long-term orientation. Second, university students from Kazakhstan higher evaluated their urban environment in the context of possibility to realise their basic values. Third, the study participants from Kazakhstan showed higher scores in such parameters of their psychological system of activity as purposefulness, satisfaction with life, need for autonomy as well as the achievement and affiliation scales. Russian university students had higher scores in reflection which is a significant factor of one's self-determination. The results obtained are discussed in the context of modern youth's personal and professional development in a specific socio-economic and cultural environment.
\end{abstract}

Key words: youth, students' value orientations, cross-cultural context.

\section{Introduction}

The collapse of the Soviet Union in 1991 generated a unique situation when 15 countries that had been a single unit before simultaneously started their own pathways to building independent national communities [1]. As Smolentseva, Huisman and Froumin highlight, all newly-born states faced similar challenges, namely, consolidating their national societies and introducing market economies [2]. These processes were accompanied by political instability, economic decline, demographic changes and even armed conflicts in most of them, having

\footnotetext{
* Corresponding author: iatamanova@yandex.ru
}

(C) The Authors, published by EDP Sciences. This is an Open Access article distributed under the terms of the Creative Commons Attribution License 4.0 (http://creativecommons.org/licenses/by/4.0/). 
a deep impact on their societies and economies. More than 25 years of the post-Soviet development in these countries have resulted in the emergence of specific political, economic and socio-cultural conditions. Moreover, in these countries there have already appeared young people who were even not "born in the USSR". They have never lived in a huge multinational united country speaking the same language.

Youth is known to be the most sensitive-to-changes age category, so it represents a major research interest in the context of the future trends of the society development. On the one hand, such a research focus is needed for better understanding of what is going on in the countries concerned. The issue of youth's personal and professional development is tightly connected with that of each country's high-quality human capital in a long-term perspective. On the other hand, globalisation processes are enhancing cooperation in different spheres between the post-soviet states as well. What do we know about people living in these countries nowadays, especially about young people who will be a driving force in their countries and, therefore, globally in a couple of decades? To what extent are they similar to each other? How much do they differ? Do they value the same things?

Cultural dimensions are believed to be the very factors that can contribute to a better understanding of the interplay between personal and environmental aspects when analysing the problem in question. The researchers emphasise that socio-cultural characteristics of human capital are becoming more and more important in identifying growth points of national economies nowadays [3]. Addressing the issue of youth's personal and professional development, taking into account their value orientations and psychological characteristics of activity, seems to be relevant to the modern world's challenges.

According to Vygotsky [4], "every human being represents a certain historical unit, living at a certain historical period and in certain historical circumstances" (p. 352). This highlights the role of socio-cultural factors in human development and means that one's sociocultural environment greatly affects the process of personal and professional development. In other words, "the environment's role in the development of higher, specifically human characteristics and forms of activity is as a source of development" (p. 351). In turn, Sorokin [5] viewed socio-cultural interaction as an indivisible integrity of three interdependent modes, namely, personality, society and culture. Therefore, as emphasised in [6], "any economic, social or cultural transformations will certainly have an effect on both personal and professional development" (p. 553).

For the purpose of this study we also address Hofstede's concept of national culture [7], whose essence is "collective programming of the mind that distinguishes the members of one group or category of people from others" (p. 5). This means that values and beliefs shared by the members of the society (at the national or local level) have a significant effect on their behavioural patterns in all life spheres.

Furthermore, recent studies revealed that educational settings also had a marked effect on university students' personal and professional development [8]. It was shown, for example, that different career orientations among master's students and doctoral students were connected with their university's orientation towards classical or engineering education. Thus, university students' socio-cultural environment has its potential in the context of their personal and professional development. The conducted studies highlighted the role of their basic values as well or, more exactly, their subjective evaluation of the possibilities to realize their basic values in the local settings. Such a subjective evaluation may differ in its profiles depending on the regional factor [6,9].

Moreover, recent studies [6] showed that the higher was young peoples' personal potential, the more possibilities they revealed in their local settings for their personal and professional development. The relationships found confirmed the idea that "not only the socio-cultural environment affects university students' personal characteristics, but also their 
subjective perception of this environment as a factor of their personal and professional development depends on their personal potential" (p. 556). The university youth with pronounced leadership qualities, purposefulness, inclination for self-organisation of their activity and inclination for reflection on it higher evaluated the possibilities to realize basic values in their socio-cultural environment. They were also more positive in their perception of possibilities for their development and self-realisation.

Thus, the paper presents a cross-cultural study on cultural values characterising socioeconomic and cultural settings of two post-soviet countries (Russia and Kazakhstan) and modern youth's basic values and parameters of their psychological system of activity.

\section{Research materials and methods}

The main research focus of the study presented was to compare university students' value orientations (at the individual level and that of culture) and parameters of their psychological system of activity. This is the first part of the research project supported by the Russian Foundation for Basic Research and aimed at studying the specific interaction of modern youth's basic values and their psychological system of activity, taking into account cultural factors of the country's socio-economic development (cultural dimensions). The three-year project involves conducting a cross-cultural analysis based on the data from three post-Soviet countries. In the year of 2018 the data were collected in Russia and Kazakhstan.

\subsection{Study design}

The study was designed as follows. The study participants were asked to fill in several questionnaires. The paper-and-pencil forms were offered in Russian. University students from Kazakhstan who participated in the study could understand the Russian language because their educational programs were implemented in Russian. The data collected were then statistically treated applying the Statistica 6.0 package. Descriptive analysis and analysis of variance (ANOVA, the F-test criterion) were used to compare the subsamples at this stage of the research project.

\subsection{Study sample}

307 university students from Tomsk (Russia) and 295 university students from Karaganda (Kazakhstan) participated in the study. Their demographic characteristics were the following. The study participants from Russia: the mean age was $20.84,47.6 \%$ were male, $51.5 \%$ were female, and three people did not indicate their sex. The study participants from Kazakhstan: the mean age was $20.87,47.8 \%$ were male, $50.8 \%$ were female, and four people did not indicate their sex either. The study participants were majoring in various subjects, but this aspect was not in question in this study.

\subsection{Research tools}

There were three research foci in collecting the data. The first one was connected with cultural dimensions (the study participants' value orientations at the level of culture). These data were collected using the Values Survey Module (VSM 2013) by Hofstede [10] and the World Values Survey questionnaire by Inglehart [11], modified by Khabibulin [12]. The former research tool is a 24-item questionnaire developed for comparing culturally influenced values, which measures six cultural dimensions, namely, power distance (large versus small), individualism versus collectivism, masculinity versus femininity, uncertainty 
avoidance (strong versus weak), long-versus short-term orientation, and indulgence versus restraint. Each item is evaluated based on a 5-point Likert-like scale where 1 is of utmost importance and 5 is of very little or no importance. Each cultural dimension or index is calculated according to the formula, for more details see [10]. Inglehart's tool modified by Khabibulin is a 13-item questionnaire which allows one to evaluate two culture-specific value orientations: traditional values versus secular-rational values and survival values versus selfexpression values. Each item is measured according to a 7-point Likert-like scale (1 means absolutely disagree and 7 means absolutely agree) [12].

The second research focus was on the study participants' value orientations at the individual level, i.e. their basic values. The research tool was developed by Bogomaz for examining one's subjective evaluation of possibilities for basic values realisation in the local settings [9]. The Basic Values Realisability technique is a 20-item instrument based on the semantic differential method originated by Osgood (see [13]) and analogous to the Noetic Orientations Test [14]. It contains 20 items corresponding to 20 basic values. Among them are have a good job, be in good health, be financially secure, have a happy family, achieve success in a profession, be respected, achieve success in your career, love and be loved, be free, feel safe, be known and famous, achieve desired goals, live full life, find meaning of your life, know everything, be an example for others, assert yourself, be unique and original, have power, and be fair. Taken together, each basic value and its opposite represent one item of the technique. The task is to evaluate each bipolar set using a 7-point Likert-like scale (3-2-1-0-1-2-3) [6].

The third research focus was on the study participants' psychological system of activity. The psychological parameters of interest were collected by using a number of questionnaires. We applied the Self-Organisation of Activity Questionnaire developed by Mandrikova [15] to evaluate the study participants' tendency to self-organisation of activity. This 25-item research tool allows measuring one's ability to plan and organise one's own activity. It has 6 subscales: planning, purposefulness, persistence, fixation, self-organisation and orientation in time. For the purposes of our study only two subscales (planning and purposefulness) were involved (10 items) and their items were evaluated based on a 5-point Likert-like scale with 1meaning absolutely disagree and 5 meaning absolutely agree. The Satisfaction with Life Scale by Diener (see [16]), translated into Russian and adapted by Osin and Leontiev [17], was used to measure the study participants' satisfaction with life. The Balanced Measure of Psychological Needs (BMPN) scale by Sheldon and Hilpert [18], an 18-item tool adapted by Leontiev, was applied to evaluate the study participants' needs for autonomy, competence and relatedness with others. In the Reflexivity Type Assessment Test by Leontiev (see [19]), a 30-item instrument developed for measuring reflective processes in a person, we used only one subscale modified for the purposes of our study ( 7 items) - systemic reflection. Finally, we used two subscales of the translated into Russian and modified version of the Personality Research Form by Jackson [20, 21], namely achievement and affiliation (6 items). To evaluate items in these research tools, a 5-point Likert-like scale was also applied.

\section{Study results and discussion}

As mentioned above, at this stage of the research project the data collected were statistically treated using descriptive analysis and analysis of variance (ANOVA, the F-test criterion). The paper presents statistically significant differences between the study subsamples (university students from Russia and Kazakhstan) and discusses them from the cross-cultural perspective.

There were three research foci (see the Research tools subsection), namely on the study participants' value orientations at the level of culture (cultural dimensions), their value 


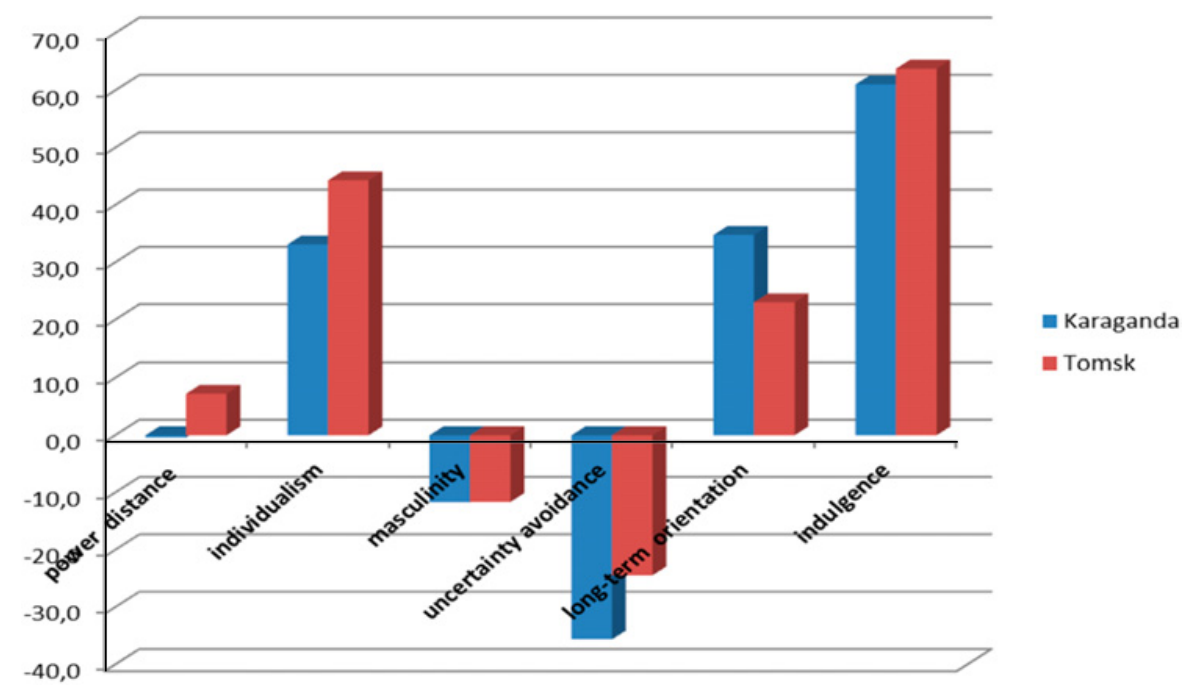

Fig. 1. Differences in Hofstede's cultural dimensions between university students from Russia (Tomsk) and Kazakhstan (Karaganda).

orientations at the individual level (basic values) and parameters of their psychological system of activity.

Cultural dimensions. Figure 1 illustrates between-group differences in cultural dimensions that were revealed using Hofstede's research tool when comparing university students from Russia $(\mathrm{N}=307)$ and Kazakhstan $(\mathrm{N}=295)$.

The ANOVA results showed some statistically significant differences $(p<0.05)$ between the subsamples in such cultural dimensions as individualism versus collectivism $(\mathrm{F}=4.034$, $p=0.045)$, uncertainty avoidance $(\mathrm{F}=4.305, p=0.038)$ and long-term versus shortterm orientation $(\mathrm{F}=5.615, p=0.018)$. As seen in Figure 1, university students from Kazakhstan can be characterised as having more collective mindsets, feeling more threatened by unknown, uncertain or ambiguous situations and being to a greater extent oriented towards long-term perspectives [10]. In contrast, university students from Russia can be described as being more individualistic, feeling less threatened by uncertainty and having short-term orientations.

Inglehart's questionnaire also allowed us to reveal a statistically significant $(p<0.05)$ difference between the study subsamples. The study participants from Kazakhstan $(\mathrm{M}=$ $4.82, \mathrm{SD}=1.01)$ were found to have more adherence to traditional values $(\mathrm{F}=32.446$, $p=0.000)$ compared to those from Russia $(\mathrm{M}=4.37, \mathrm{SD}=0.89)$. Based on [10], we can conclude that university youth from Kazakhstan more appreciate traditional parent-child relations and traditional family values and norms. In turn, this is in line with the results obtained by Hoftede's measure. In contrast, university students from Russia are to a larger extent oriented towards post-materialist values.

Basic values. Figure 2 shows between-group differences in the study participants' value orientations at the individual level. These are the scores in their subjective evaluation of basic values realisability in their local settings. As mentioned in [6], such a characteristic can describe the potential of one's socio- cultural environment in terms of one's personal and professional development. The subjective perception of one's local settings with taking into account one's basic values seems to be essential for shedding some light on the problem of initiating human activity and achieving one's meaningful goals. 
Table 1. The study participants' subjective evaluation of basic values realisability in the local settings.

\begin{tabular}{|l|c|c|c|c|c|c|}
\hline \multirow{2}{*}{ Basic values } & \multicolumn{2}{|l|}{ Russia $(\mathbf{N}=\mathbf{3 0 7})$} & \multicolumn{2}{l|}{ Kazakhstan $(\mathbf{N}=\mathbf{2 9 5})$} & \multirow{2}{*}{ F } & \multirow{2}{*}{ SD } \\
\cline { 2 - 6 } & Mean & SD & Mean & SD & & \\
\hline Have a good job & 5.95 & 1.41 & 6.37 & 1.05 & 16.561 & 0.000 \\
\hline Be in good health & 5.65 & 1.60 & 6.26 & 1.29 & 24.776 & 0.000 \\
\hline Be financially secure & 5.42 & 1.67 & 5.60 & 1.82 & 1.558 & 0.212 \\
\hline Have a happy family & 5.93 & 1.47 & 6.22 & 1.47 & 5.366 & 0.021 \\
\hline $\begin{array}{l}\text { Achieve success in a } \\
\text { profession }\end{array}$ & 5.96 & 1.35 & 6.19 & 1.34 & 4.394 & 0.036 \\
\hline Be respected & 5.67 & 1.42 & 5.66 & 1.61 & 0.019 & 0.890 \\
\hline $\begin{array}{l}\text { Achieve success in your } \\
\text { career }\end{array}$ & 5.91 & 1.35 & 6.18 & 1.30 & 5.948 & 0.015 \\
\hline Love and be loved & 6.09 & 1.27 & 6.33 & 1.22 & 4.967 & 0.026 \\
\hline Be free & 5.24 & 1.70 & 5.43 & 1.73 & 1.863 & 0.173 \\
\hline Feel safe & 5.62 & 1.50 & 6.06 & 1.41 & 13.328 & 0.000 \\
\hline Be known and famous & 4.84 & 1.72 & 4.79 & 1.74 & 0.116 & 0.733 \\
\hline Achieve desired goals & 5.83 & 1.45 & 6.02 & 1.54 & 2.408 & 0.121 \\
\hline Live full life & 5.93 & 1.45 & 6.19 & 1.45 & 4.726 & 0.030 \\
\hline Find meaning of your life & 5.71 & 1.53 & 6.11 & 1.40 & 10.456 & 0.001 \\
\hline Know everything & 5.62 & 1.66 & 5.90 & 1.53 & 4.571 & 0.033 \\
\hline Be an example for others & 5.58 & 1.30 & 5.67 & 1.51 & 0.538 & 0.464 \\
\hline Assert yourself & 5.88 & 1.22 & 6.13 & 1.15 & 6.222 & 0.013 \\
\hline Be unique and original & 4.79 & 1.97 & 5.14 & 1.93 & 4.491 & 0.035 \\
\hline Have power & 4.70 & 1.60 & 4.92 & 1.75 & 2.535 & 0.112 \\
\hline Be fair & 5.89 & 1.25 & 6.19 & 1.28 & 8.084 & 0.005 \\
\hline
\end{tabular}

The ANOVA results showed that there were statistically significant $(p<0.05)$ differences in the subjective evaluation of basic values realisability between the study subsamples. The study participants from Kazakhstan higher evaluated their urban environment for realising such basic values as being unique and original $(\mathrm{F}=4.491$, $p=0.035)$, knowing everything $(\mathrm{F}=4.571, p=0.033)$, feeling safe $(\mathrm{F}=13.328, p=$ $0.000)$, finding meaning of your life $(\mathrm{F}=10.456, p=0.001)$, asserting yourself $(\mathrm{F}=6.222$, $p=0.013)$, achieving success in your career $(\mathrm{F}=5.948, p=0.015)$, being fair $(\mathrm{F}=8.084$, $p=0.005)$, living full life $(\mathrm{F}=4.726, p=0.030)$, achieving success in a profession $(\mathrm{F}=$ 4.394, $p=0.036)$, having a happy family $(\mathrm{F}=5.366, p=0.021)$, being in good health $(\mathrm{F}=24.776, p=0.000)$, loving and being loved $(\mathrm{F}=4.967, p=0.026)$ and having a good job $(\mathrm{F}=16.561, p=0.000)$. Table 1 presents basic values realisability means, standard deviations and ANOVA results for the study subsamples.

The study participants from Kazakhstan higher evaluated their local settings for realising most of the basic values in question compared to those from Russia, as seen in Table 1 and Fig. 2. On the one hand, this may be a consequence of their adherence to traditional values and norms, including traditional ways of understanding the essence of their personal and professional development as well. On the other hand, such a result may reflect their less realistic views on their local settings. 


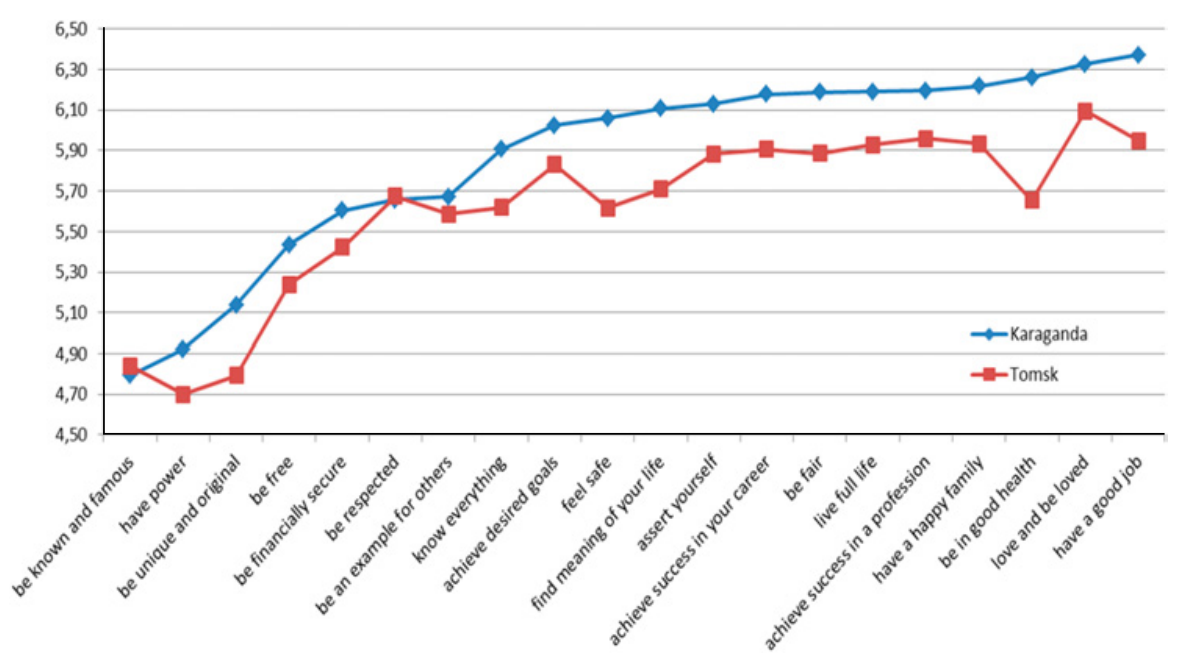

Fig. 2. Differences in the subjective evaluation of basic values realisability in the local settings between university students from Russia (Tomsk) and Kazakhstan (Karaganda).

Table 2. The study participants' psychological system of activity.

\begin{tabular}{|l|c|c|c|c|c|c|}
\hline \multirow{2}{*}{ Parameters } & \multicolumn{2}{|l|}{ Russia $(\mathbf{N}=\mathbf{3 0 7})$} & \multicolumn{2}{c|}{ Kazakhstan $(\mathbf{N}=\mathbf{2 9 5})$} & \multirow{2}{*}{ F } & \multirow{2}{*}{$\boldsymbol{p}$} \\
\cline { 2 - 5 } & Mean & SD & Mean & SD & & \\
\hline Purposefulness & 3.95 & 0.78 & 4.09 & 0.66 & 5.756 & 0.017 \\
\hline Planning & 3.21 & 0.98 & 3.32 & 0.88 & 1.824 & 0.177 \\
\hline Systemic reflection & 4.03 & 0.58 & 3.88 & 0.60 & 8.904 & 0.003 \\
\hline Satisfaction with life & 3.34 & 0.75 & 3.50 & 0.81 & 5.969 & 0.015 \\
\hline Readiness for activity & 3.64 & 0.51 & 3.70 & 0.54 & 1.771 & 0.184 \\
\hline Need for achievement & 3.96 & 0.71 & 4.20 & 0.65 & 18.222 & 0.000 \\
\hline Need for affiliation & 3.99 & 0.78 & 4.14 & 0.74 & 5.685 & 0.017 \\
\hline
\end{tabular}

One more issue of interest was connected with the study participants' psychological system of activity. As described in the Research tools subsection, there were a number of parameters in question. First, statistically significant $(p<0.05)$ between-group differences were found in such parameters as purposefulness $(\mathrm{F}=5.756, p=0.017)$, systemic reflection $(\mathrm{F}=8.904, p=0.003)$ and satisfaction with life $(\mathrm{F}=5.969, p=0.015)$. The study participants from Kazakhstan had higher scores in purposefulness $(\mathrm{M}=4.09, \mathrm{SD}=0.66)$ and satisfaction with life $(\mathrm{M}=3.50, \mathrm{SD}=0.81)$, while the ones from Russia were more disposed to systemic reflection $(\mathrm{M}=4.03, \mathrm{SD}=0.58)$. Second, the study participants from Kazakhstan showed higher scores in their needs for achievement $(\mathrm{M}=4.20, \mathrm{SD}=$ $0.65)$ and affiliation $(\mathrm{M}=4.14, \mathrm{SD}=0.74)$ compared to the ones from Russia $(\mathrm{M}=3.96$, $\mathrm{SD}=0.71$ and $\mathrm{M}=3.99, \mathrm{SD}=0.78$, respectively). The statistically significant betweengroup differences were the following: $\mathrm{F}=18.222, p=0.000$ for the achievement scale and $\mathrm{F}=5.685, p=0.017$ for the affiliation one. The study participants' needs for autonomy also differed at the statistically significant level $(p<0.05)$. The university students from Kazakhstan had higher scores in their need for autonomy $(\mathrm{F}=9.279, p=0.002)$. For more details see Table 2. 
Interpreting the identified differences in parameters of the study participants' psychological system of activity, taking into account their value orientations at the individual level and that of culture, we would like to emphasise the following. Higher scores in the achievement and affiliation scales in university students from Kazakhstan may be connected with their greater adherence to traditional values compared to their counterparts from Russia. It is these traditional views that may determine young people's priorities in their personal and professional development as well as their life strategies. Meanwhile, they had higher scores in their need for autonomy; this may signal their desire to rely to a greater extent on their own.

In addition, higher scores in purposefulness and planning among university students from Kazakhstan may be also connected with their adherence to traditional values and more pronounced long-term orientation and uncertainty avoidance compared to those from Russia. Such value orientations may result in a desire to follow a certain algorithm to achieve their purposes. In contrast, higher scores in systemic reflection among university students from Russia may demonstrate more flexibility in making decisions to meet the demands of the modern changing world. This is also in line with their short-term orientation and lower scores in uncertainty avoidance.

\section{Conclusions}

Thus, the study conducted enabled us to reveal some statistically significant differences between young people from Russia and Kazakhstan in their value orientations at the individual level and that of culture, as well as in their parameters of the psychological system of activity. Such a complex cross-cultural analysis involving young people from the postSoviet countries has been undertaken for the first time. The paper presents only some results of the first stage of the three-year research project and this is one of the limitations. Further analysis of the data collected will be focused on identifying within-group relationships between the parameters in question to shed more light on the interplay between young people's value orientations and their parameters of the psychological system of activity. The relationship between their value orientations (at the individual level and that of culture) and personal characteristics is of particular importance for creating psychological support programs in higher educational settings to enhance university youth's personal readiness for activity.

The paper has been prepared within the research project (18-013-00781) supported by the Russian Foundation for Basic Research.

\section{References}

[1] A. Pavlenko, Russian Linguistics 32(1), 59-80 (2008)

[2] A. Smolentseva, J. Huisman, I. Froumin, 25 Years of Transformations of Higher Education Systems in Post-Soviet Countries (Palgrave Macmillan, Cham, 2018)

[3] A.A. Auzan, J. New Econ. Assoc. 2(26), 243-248 (2015)

[4] L.S. Vygotsky, The Vygotsky Reader (Blackwell, Oxford, 1934/1994)

[5] P.A. Sorokin, Society, Culture and Personality: Their Structure and Dynamics (Harper, New York, 1947)

[6] S. Bogomaz, N. Kozlova, I. Atamanova, Procedia - Social and Behavioral Sciences 214, 552-558 (2015) 
[7] G. Hofstede, G.J. Hofstede, M. Minkov, Cultures and Organizations: Software of The Mind (McGraw-Hill, New York, 2010)

[8] I.V. Atamanova, O.N. Starichenko, S.A. Bogomaz, Tomsk State University Journal 367, 128-135 (2013)

[9] S.A. Bogomaz, Proceedings of V All-Russian scientific-practical conference with foreign researchers' participation " $A$ man and the world: Psychology of conflict, uncertainty and risk of innovation" (ERGO, Izhevsk, 2014)

[10] G. Hofstede, M. Minkov, Values survey module 2013. Manual (Geert Hofstede BV, 2013) http://geerthof stede.com/wp-content/uploads/2016/07/ManualVSM-2013.pdf

[11] R. Inglehart, C. Welzel, Modernization, Cultural Change, and Democracy: The Human Development Sequence (Cambridge University Press, New York, 2005)

[12] O.S. Deyneka, R.K. Khabibulin, Modern Problems of Science and Education 1-1, 1525 (2015)

[13] C.E. Osgood, G. Suci, P. Tannenbaum, The Measurement of Meaning (University of Illinois Press, Urbana, 1957)

[14] D.A. Leont'ev, Test Smyslozhiznennykh Orientatsiy (SZhO) [The Noetic Orientations Test (NOT)] (Smysl, Moscow, 1992)

[15] E. Yu. Mandrikova, Oprosnik Samoorganisatsii Deyatel'nosti [The Self-organization of Activity Questionnaire] (Smysl, Moscow, 2007)

[16] E. Diener, R. Emmons, R. Larsen, S. Griffin, Journal of Personality Assessment 49, 71-75 (1985)

[17] E.N. Osin, D.A. Leontiev, Materialy III Vserossiyskogo Sotsiologicheskogo Kongressa [Proceedings of III All-Russian Sociology Congress] (Sociology Institute of RAN, Moscow, 2008)

[18] K.M. Sheldon, J.C. Hilpert, Motivation and Emotion 36(4), 439-451 (2012)

[19] D.A. Leontiev, E.N. Osin, Psychology. Journal of the Higher School of Economics 11(4), 110-135 (2014)

[20] D.N. Jackson, Personality Research Form Manual (3 ${ }^{\text {rd }}$ ed.) (Research Psychologists Press, Port Huron, 1984)

[21] I.M. Kondakov, Zhurnal Prikladnoi Psikhologii [J. Appl. Psychology] 4, 99-113 (1998) 